\title{
I mmunophenotype of hematopoietic stem cells from placental/umbilical cord blood after culture
}

P. Pranke ${ }^{1,3,4}$, J. Hendrikx ${ }^{4}$,

G. Debnath ${ }^{4}$, G. Alespeiti ${ }^{4}$,

P. Rubinstein ${ }^{5}$, N. Nardi ${ }^{2}$ and J. Visser ${ }^{4}$
Correspondence

P. Pranke

Laboratório de Hematologia

Faculdade de Farmácia, UFRGS

Av. Ipiranga, 2752

90160-000 Porto Alegre, RS

Brasil

Fax: +55-51-3316-5437

E-mail: ppranke@adufrgs.ufrgs.br

Research supported by New York Blood Center, New York, USA, and CAPES.

Received January 21, 2005 Accepted August 15, 2005

\author{
${ }^{1}$ Laboratório de Hematologia, Faculdade de Farmácia, ${ }^{2}$ Departamento de Genética, \\ Universidade Federal do Rio Grande do Sul, Porto Alegre, RS, Brasil \\ ${ }^{3}$ Faculdade de Farmácia, Pontifícia Universidade Católica do Rio Grande do Sul, \\ Porto Alegre, RS, Brasil \\ ${ }^{4}$ Stem Cell Biology, ${ }^{5}$ Immunogenetics, New York Blood Center, New York, NY, USA
}

\section{Abstract}

Identification and enumeration of human hematopoietic stem cells remain problematic, since in vitro and in vivo stem cell assays have different outcomes. We determined if the altered expression of adhesion molecules during stem cell expansion could be a reason for the discrepancy. $\mathrm{CD} 34^{+} \mathrm{CD} 38^{-}$and $\mathrm{CD} 34^{+} \mathrm{CD} 38^{+}$cells from umbilical cord blood were analyzed before and after culture with thrombopoietin (TPO), FLT-3 ligand (FL) and kit ligand (KL; or stem cell factor) in different combinations: TPO + FL + KL, TPO + FL and TPO, at concentrations of $50 \mathrm{ng} / \mathrm{mL}$ each. Cells were immunophenotyped by four-color fluorescence using antibodies against CD11c, CD31, CD49e, CD61, CD62L, CD117, and HLA-DR. Low-density cord blood contained $1.4 \pm 0.9 \% \mathrm{CD}^{+} 4^{+}$cells, $2.6 \pm 2.1 \%$ of which were CD38negative. $\mathrm{CD}^{+}{ }^{+}$cells were isolated using immuno-magnetic beads and cultured for up to 7 days. The TPO + FL + KL combination presented the best condition for maintenance of stem cells. The total cell number increased $4.3 \pm 1.8$-fold, but the number of viable CD34 ${ }^{+}$ cells decreased by $46 \pm 25 \%$. On the other hand, the fraction of CD $34^{+} \mathrm{CD} 38^{-}$cells became $52.0 \pm 29 \%$ of all $\mathrm{CD} 34^{+}$cells. The absolute number of $\mathrm{CD} 34^{+} \mathrm{CD} 38^{-}$cells was expanded on average $15 \pm$ 12-fold when $\mathrm{CD} 34^{+}$cells were cultured with $\mathrm{TPO}+\mathrm{FL}+\mathrm{KL}$ for 7 days. The expression of CD62L, HLA-DR and CD117 was modulated after culture, particularly with TPO + FL + KL, explaining differences between the adhesion and engraftment of primary and cultured candidate stem cells. We conclude that culture of $\mathrm{CD} 34^{+}$cells with TPO + $\mathrm{FL}+\mathrm{KL}$ results in a significant increase in the number of candidate stem cells with the $\mathrm{CD} 34^{+} \mathrm{CD} 38^{-}$phenotype.

\section{Introduction}

A small population of primitive hematopoietic stem cells (HSCs) is present in the bone marrow. These cells are defined by their ability to self-renew as well as to differentiate into committed progenitors of the
Key words

- Hematopoietic stem cells

- CD34+CD38- cells

- Human umbilical cord blood

- Ex vivo expansion

- Adhesion molecules ..................... 
human umbilical cord blood (HUCB) has been clinically investigated as an alternative source of HSCs for allogeneic transplantation of patients lacking a human leukocyte antigen-matched marrow donor. However, the number of HSCs in HUCB samples is limited. Identification of conditions that support the self-renewal and expansion of human HSCs remains a major goal of experimental and clinical hematology. Expansion of human stem cells in ex vivo culture will likely have important applications in transplantation, stem cell marking, and gene therapy (2). The CD34+ protein is a surface glycoprotein expressed on HSCs and progenitor cells in early developmental stages in HUCB and bone marrow, as well as on endothelial cells. The $\mathrm{CD} 34^{+} \mathrm{CD} 38^{-}$immunophenotype defines a primitive subpopulation of progenitor cells in fetal liver and fetal or adult bone marrow (3-5). About $1 \%$ of bone marrow cells express CD34, and generally less than $1 \%$ of these cells are CD38-negative. Hence, the frequency of the $\mathrm{CD} 34^{+} \mathrm{CD} 38^{-}$ population is about 1 in 10,000 , or even lower. Phenotypic analyses of several cell surface markers reveal that even this rare population is heterogeneous (6). Ex vivo culture is a crucial component of several clinical applications of stem/progenitor cells. A single stem cell has been proposed to be capable of more than 50 cell divisions or doublings in vivo and as such has the capacity to generate up to $10^{15}$ cells, or sufficient cells for up to 60 years. The proliferation and differentiation of cells is controlled by a group of hematopoietic growth factors. Replication of this enormous cell amplification with hematopoietic growth factors in vitro would allow the generation of large numbers of cells that could be used for a variety of clinical applications (7).

Several culture systems have been developed to expand HSCs (5). Piacibello et al. (1) reported the differential ability of FLT-3 ligand (FL), thrombopoietin (TPO), kit ligand (KL), and interleukin-3 (IL-3), alone or combined, to support different stages of hematopoiesis in long-term stroma-free suspension cultures of HUCB CD $34^{+}$cells. Several studies have described the effects of TPO alone in culture, which can stimulate early proliferation, survival or differentiation of progenitor cells in cord blood or bone marrow (8).

The proliferation and differentiation of HSCs are controlled not only by soluble growth factors, but also by adhesion to stromal cells and matrix molecules. The expression of adhesion molecules has attracted special attention, as their expression on HSCs and on endothelial and stromal cells plays a pivotal role in the process (9). These molecules permit the interaction with various regulatory elements present in the microenvironment, which includes stromal cells, extracellular matrix molecules and soluble regulatory factors such as cytokines and growth/differentiation factors (10).

Adhesion molecules include integrins, selectins and molecules from the immunoglobulin superfamily.

The objective of the present study was to investigate the behavior of umbilical cord blood $\mathrm{CD} 34^{+} \mathrm{CD} 38^{+}$and $\mathrm{CD} 34^{+} \mathrm{CD} 38^{-}$cells cultured with different combinations of growth factors, with respect to their viability, immunophenotype and self-renewal and differentiation capacities. Adhesion molecules representing the integrins (CD11c or integrin $\alpha$-chain, CD49e or $\alpha-5$ chain and CD61 or $B-3$ chain), selectins (CD62L or LECAM-1) and the immunoglobulin superfamily (CD31 or PECAM-1) were analyzed. The expression of HLA-DR and CD117 (ckit or stem cell factor receptor), which represent differentiation markers for $\mathrm{CD} 34^{+}$cells, was also investigated.

\section{Material and Methods}

\section{Human umbilical cord blood cells}

A total of 27 cord blood samples were used in this study. Umbilical cord blood 
samples obtained after deliveries ( $\geq 29$ weeks) were collected in sterile bags containing citrate-phosphate-dextrose. Samples were obtained at the Umbilical Cord Blood Bank of the New York Blood Center (New York, NY, USA). Blood was collected according to an Institutional Review Board-approved protocol. Units that are not used in the Placental Blood Program are destined to research. Since collection is performed on delivered placentas, the blood is considered discarded tissue. Blood not used for clinical transplants is not identified and is used without informed consent.

\section{Isolation of $\mathrm{CD}^{3} 4^{+}$cells}

Low-density mononuclear cells (MNCs) were isolated using density gradient centrifugation on Ficoll-Paque $1.077 \mathrm{~g} / \mathrm{cm}^{2}$ (Amersham Pharmacia, Piscataway, NJ, USA), modified by the addition of $1 \mathrm{M}$ phosphate buffer, $\mathrm{pH}$ 7.6, to the Dulbecco's phosphate-buffered saline (GibcoBRL, Gaithersburg, MD, USA) used to dilute the blood. This modification improved the isolation of the mononuclear fraction, since the harvested cell population contained 50\% less reticulocytes and less than 50 to $60 \%$ erythrocytes. CD $34^{+}$cells were harvested from the MNCs using automated magnetic cell sorting (MACS) High Gradient Magnetic Separation Columns for positive selection (Miltenyi Biotec, Bergisch Gladbach, North RhineWestphalia, Germany). The magnetically labeled cells were enriched by passing them twice through positive selection columns.

\section{Antibodies}

For the analysis of $\mathrm{CD}^{2} 4^{+}$cells, monoclonal antibodies (PharMingen/Becton Dickinson, San Jose, CA, USA) specific for the following human antigens were used: CD34/ FITC (clone 34374X lot MO46959), CD38/ APC (clone HIT2), CD11c/PE (clone BIY6), CD31/PE (clone WM59), CD49e/PE (clone IIA1), CD61/PE (clone VI-PL2), CD62L/PE (clone Dreg 56), CD117/PE (clone YB5.B8), and HLA-DR/PE (clone G46-6), as well as isotype control antibodies (clones MOPC-21): mouse IgG1,k/FITC, IgG1,k/PE, and IgG1,k/APC.

\section{Flow cytometry analyses}

Processing for four-color fluorescence flow cytometry was done within $36 \mathrm{~h}$ of collection using at least $10,000 \mathrm{CD} 34^{+}$cells, before culture and after 4 and 7 days of culture. Cells were incubated with anti-CD34/ FITC and anti-CD38/APC antibodies combined with PE-conjugated antibodies specific for CD11c, CD31, CD49e, CD61, CD62L, CD117, or HLA-DR. All incubations were done for $30 \mathrm{~min}$ at $4^{\circ} \mathrm{C}$, and cells were washed with phosphate-bufered saline. 7-Aminoactinomycin D (Molecular Probes, Inc., Eugene, OR, USA) at a final concentration of 1 $\mu \mathrm{g} / \mathrm{mL}$ was used to identify dead cells. Flow cytometry was performed on a FACScalibur instrument (Becton Dickinson) equipped with an argon-ion laser tuned at $488 \mathrm{~nm}$. The CELLQuest software (Becton Dickinson) was used for data analysis. Between 5,000 and 50,000 events were collected for each analysis. The gating strategy used can be summarized as follows. First, viable cells were gated, followed by a gating of the cell cluster in forward and side scatter, and using the FITC channel of $\mathrm{CD} 34^{+}$cells. Among the $\mathrm{CD} 34^{+}$cells, CD38-negative and CD38positive cells were gated and the frequency of cells positive for the third antibody was analyzed.

Analysis of the cell frequency among the different populations was done using the Hendrikx and Pranke Plot program (data not shown) (11), a novel method to facilitate visualization of complex flow cytometry data sets across four dimensions in just a few graphs. In short, samples are divided into clusters, and the mean fluorescence of the cluster versus the frequency of the cluster is 
plotted per cluster. In addition, data and cell suspension are shown as third and fourth dimensions, identified as symbol shape and symbol color.

\section{Ex-vivo expansion cultures}

MACS-isolated CD34+ cells were cultured in 24-well plates (Multiwell ${ }^{\mathrm{TM}}$ Tissue Culture Plate, Becton Dickinson) in $2 \mathrm{~mL}$ Iscove's modified Dulbecco's medium with L-glutamine and $25 \mathrm{mM}$ HEPES buffer (GibcoBRL), supplemented with hydrocortisone $\left(10^{-5} \mathrm{M}\right.$, Sigma, St. Louis, MO, USA), 2-mercaptoethanol $\left(5.5 \times 10^{-5} \mathrm{M}\right.$, GibcoBRL), penicillin G (100 units $/ \mathrm{mL}$, GibcoBRL), streptomycin $(0.1 \mathrm{mg} / \mathrm{mL}$,

Table 1. Volume of the umbilical cord blood samples and frequency of mononuclear and $\mathrm{CD} 34^{+}$cells obtained after the isolation on Ficoll-Paque and automated magnetic cell sorting columns, respectively.

\begin{tabular}{|c|c|c|}
\hline & Mean \pm SD & Range \\
\hline Blood volume $(\mathrm{mL})$ & $45.2 \pm 5.6$ & $32-57$ \\
\hline $\operatorname{MNC}\left(\times 10^{7}\right)$ & $10.4 \pm 5.7$ & $2.5-23.0$ \\
\hline MNC (/mm³ blood $)$ & $2287 \pm 1132$ & $532-4510$ \\
\hline CD34+ cells $\left(\times 10^{6}\right)$ & $1.3 \pm 0.8$ & $0.3-4.0$ \\
\hline $\mathrm{CD} 34^{+}$cells $\left(/ \mathrm{mm}^{3}\right.$ blood $)$ & $28.0 \pm 16.7$ & $6.4-85.0$ \\
\hline$\% \mathrm{CD} 4^{+}$cells among MNCs & $1.4 \pm 0.9$ & $0.4-4.9$ \\
\hline
\end{tabular}

Data are reported as mean $\pm \mathrm{SD}$ for $\mathrm{N}=27 . \mathrm{MNC}=$ mononuclear cells.
GibcoBRL) and $1 \%$ bovine serum albumin (Sigma). Cell concentrations varied between 2.5 and $5.5 \times 105 /$ well. Human growth factors used were: TPO (Kirin Brewery, Kirin Brewery, Chuo-ku, Tokyo, Japan), FL (Amgen Inc., Thousand Oaks, CA, USA) and KL (Amgen Inc.), also called steel factor or stem cell factor, at concentrations of 50 $\mathrm{ng} / \mathrm{mL}$ each. The combination of hematopoietic growth factors used were: $\mathrm{TPO}+\mathrm{FL}$ $+\mathrm{KL} ; \mathrm{TPO}+\mathrm{FL}$ and TPO. The cultures were maintained at $37^{\circ} \mathrm{C}$ and $5 \% \mathrm{CO}_{2}$ in a humidified atmosphere and analyzed on days 4 and 7 .

\section{Results}

$\mathrm{CD} 34^{+}$cells were isolated from a total of 27 cord blood samples, and the number of MNCs as well as CD34+ cells was analyzed in a Neubauer chamber. As shown in Table 1 , the concentration of $\mathrm{CD} 34^{+}$cells was 28 cells $/ \mathrm{mm}^{3}$ of cord blood (yield after Ficoll and MACS procedure). The purity of this cell fraction was $93.2 \pm 3.6 \%(87-99 \% ; \mathrm{N}=$ $10)$. Since $22.2 \pm 11.3 \%$ (12.5-50.6\%) of the $\mathrm{CD}^{+}{ }^{+}$cells were dead, the average frequency of viable $\mathrm{CD}^{+} 4^{+}$among total cells was $71.0 \pm 13.1 \%(39.4-86.5 \%)$.

$\mathrm{CD} 34^{+}$cells were cultured with three
Figure 1. Effect of different combinations of growth factors on cell proliferation after 4 and 7 days in culture. Sixteen different units of cord blood were used, and samples 2, 3, 4 and 11 were split into two different cultures (a and b), using 2 combinations of growth factors. TPO = thrombopoietin; FL = FLT-3 ligand; $\mathrm{KL}=$ kit ligand.

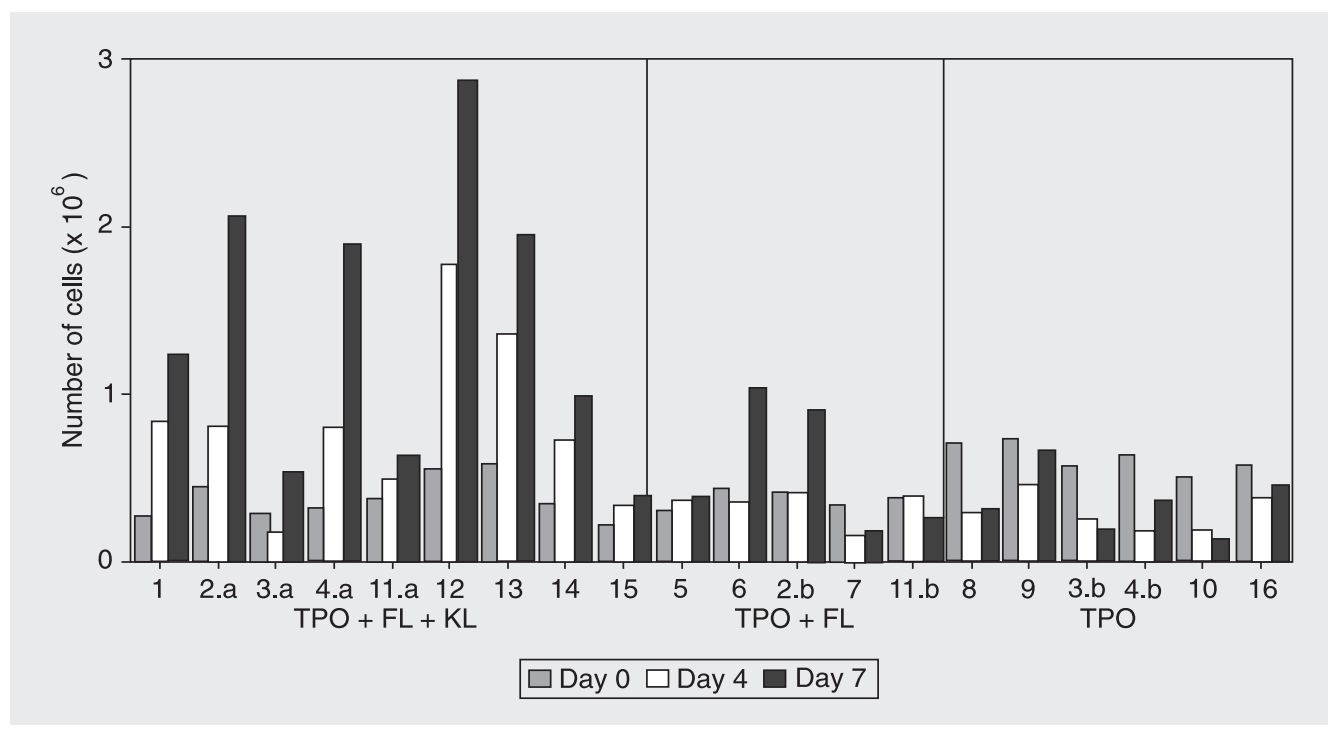


combinations of growth factors (Figure 1). With TPO + FL + KL, the average increase in cell number in 9 samples studied was 3.55 \pm 1.6 -fold after 7 days of culture. Only 1 sample (3.a) showed a 0.56-fold decrease in cell number on day 4, but by day 7 the number of the cells in this sample had increased. The observation of individual cultures (Figure 1) showed some heterogeneity among samples, particularly when TPO + FL was used. With this combination of growth factors, the total number of cells changed very little until day 4 . From day 4 until day 7 of culture, however, in one sample the cell number decreased 0.65 -fold, in 2 samples it showed no major variation, and in the remaining 2 a considerable increase $(2.57$ \pm 0.5 -fold) in total cell number was observed. Considering the total culture period, in 2 samples the cell number decreased 0.59 \pm 0.11 -fold and in 3 of them it increased 1.92 \pm 0.56 -fold. In all 6 samples cultured with TPO, the total cell number decreased during the first 4 days. After that, in 4 of them there was an increase, not enough, however, to reach the original number. Taken as a whole, cell numbers decreased $0.55 \pm 0.26$-fold with TPO only.

Further analyses were done in 10 of the samples. Three of them were separated into two cultures submitted to different treat- ments. The analysis of cell viability during the period of culture (Table 2) showed that, for cultures in the presence of TPO + FL + $\mathrm{KL}$, the absolute number of viable cells increased $4.27 \pm 1.82$-fold in the 4 samples studied. In one sample (3.a) the number of viable cells decreased 0.5 -fold from day 0 to day 4, but increased 3.4-fold from the 4th to the 7th day. In cultures with TPO + FL, the number of viable cells increased $1.94 \pm 0.56$ fold in 3 samples, and decreased 0.76-fold in one sample. In the 5 samples cultured with TPO, the number of viable cells decreased $0.35 \pm 0.28$-fold .

The viability of $\mathrm{CD} 34^{+}$cells was increased after culture with $\mathrm{TPO}+\mathrm{FL}+\mathrm{KL}$ and with $\mathrm{TPO}+\mathrm{FL}$, and maintained in the presence of TPO, but the frequency of viable CD $34^{+}$ cells among total viable cells decreased (Table 2). From day 0 to day 7 of culture with TPO + FL + KL, the number of viable $\mathrm{CD} 4^{+}$cells decreased $0.46 \pm 0.25$-fold in the 4 samples studied, whereas with TPO + FL and TPO alone this decrease was $0.30 \pm$ 0.12 - and $0.13 \pm 0.08$-fold, respectively.

Of particular interest are the results regarding the frequency of $\mathrm{CD} 34^{+} \mathrm{CD} 38^{-}$cells during the culture period. As shown in Table 2 , the number of viable $\mathrm{CD} 34^{+} \mathrm{CD} 38^{-}$cells increased in some of the culture conditions. With TPO + FL + KL, this increase was

Table 2. Total and $\mathrm{CD} 34^{+}$cell viability and frequency of $\mathrm{CD} 34^{+}$and $\mathrm{CD} 34^{+} \mathrm{CD} 38^{-}$cells on day 0 and after culture with three different combinations of growth factors.

\begin{tabular}{|c|c|c|c|c|c|c|c|}
\hline & \multirow[b]{2}{*}{ Day 0} & \multicolumn{2}{|c|}{$\mathrm{TPO}+\mathrm{FL}+\mathrm{KL}(\mathrm{N}=4)$} & \multicolumn{2}{|c|}{$\mathrm{TPO}+\mathrm{FL}(\mathrm{N}=4)$} & \multicolumn{2}{|c|}{ TPO $(\mathrm{N}=5)$} \\
\hline & & Day 4 & Day 7 & Day 4 & Day 7 & Day 4 & Day 7 \\
\hline Total cell viability & $\begin{array}{c}76.1 \pm 13.0 \\
(N=10)\end{array}$ & $81.7 \pm 6.0$ & $78.6 \pm 5.8$ & $68.9 \pm 17.6$ & $72.2 \pm 8.1$ & $54.2 \pm 14.9$ & $52.9 \pm 13.0$ \\
\hline $\mathrm{CD} 4^{+}$cell viability & $\begin{array}{c}76.0 \pm 12.7 \\
(N=10)\end{array}$ & $90.2 \pm 4.0$ & $92.3 \pm 5.9$ & $83.2 \pm 7.5$ & $87.7 \pm 7.0$ & $78.6 \pm 11.0$ & $79.8 \pm 14.0$ \\
\hline $\begin{array}{l}\text { Viable CD } 34^{+} \text {cells } \\
\text { among viable cells }\end{array}$ & $\begin{array}{r}93.3 \pm 2.1 \\
(N=10)\end{array}$ & $35.0 \pm 23.3$ & $10.9 \pm 5.0$ & $63.9 \pm 16.9$ & $23.9 \pm 22.0$ & $80.7 \pm 7.0$ & $41.8 \pm 21.1$ \\
\hline $\begin{array}{l}\text { Viable CD } 38^{-} \text {cells } \\
\text { among CD } 34^{+} \text {cells }\end{array}$ & $\begin{array}{l}2.6 \pm 2.1 \\
(N=8)\end{array}$ & $16.0 \pm 19.9$ & $52.0 \pm 28.8$ & $1.6 \pm 0.9$ & $9.1 \pm 8.6$ & $1.8 \pm 1.6$ & $2.5 \pm 2.4$ \\
\hline
\end{tabular}

Data are reported as $\% \pm \mathrm{SD}$. TPO = thrombopoietin; FL = FLT-3 ligand; $\mathrm{KL}=$ kit ligand. 
$14.59 \pm 11.81$-fold in 3 samples. In one sample, cell numbers were not determined on day 0 , but from day 4 to day 7 the number of viable $\mathrm{CD} 34^{+} \mathrm{CD} 38$ - cells increased 4.27fold. In one sample (3.a), the number of $\mathrm{CD} 34^{+} \mathrm{CD} 38^{-}$cells decreased 0.23 -fold from day 0 to day 4, but increased 23-fold until day 7. For cultures with TPO + FL, these cells increased $2.79 \pm 2.29$-fold in the 3 samples studied from day 0 to day 7 and in one sample for which the analysis was not done on day 0 , they increased 1.22 -fold from day 4 to day 7 . In the presence of TPO, however, the number of viable $\mathrm{CD} 34^{+} \mathrm{CD} 38^{-}$ cells decreased $0.26 \pm 0.31$-fold in 5 samples.

The expansion and proliferation of CD34 ${ }^{+}$CD38- cells were significantly increased in the presence of $\mathrm{TPO}+\mathrm{FL}+\mathrm{KL}$ as compared to the other two combinations of growth factors. An interesting correlation can be seen between this effect and total increase in cell numbers, which is directly proportional to the increase or decrease in CD $34{ }^{+} \mathrm{CD} 38-$ cells (Figures 1 and 2). When $\mathrm{TPO}+\mathrm{FL}+\mathrm{KL}$ were used, in 4 samples, total cell numbers as well as $\mathrm{CD} 34^{+} \mathrm{CD} 38^{-}$ cells were gradually increased during culture. In Figure 1, it can be seen that total cell numbers increased from the first to the fourth day in 8 of 9 samples cultured in the presence of TPO + FL + KL. Only one sample (3.a) showed a 0.6-fold decrease in cell number until the fourth day in culture, but this number increased around 3.4-fold from day 4 to day 7 . The same pattern was observed for $\mathrm{CD}^{2} 4^{+} \mathrm{CD} 38^{-}$cells (Figure 2), as well as in cultures where TPO + FL or TPO alone were used as growth factors. On the other hand, no correlation was observed between the initial number of $\mathrm{CD} 34^{+} \mathrm{CD} 38^{-}$cells and total cell growth or with the expansion of the CD $34^{+} \mathrm{CD} 38^{-}$cells. Similarly, no correlation was detected between the initial number of viable $\mathrm{CD} 34^{+}$cells and cell growth or number of CD $34^{+} \mathrm{CD} 38^{-}$cells (results not shown).

The immunophenotypic profile of freshly isolated $\mathrm{CD} 34^{+} \mathrm{CD} 38^{+}$and $\mathrm{CD} 34^{+} \mathrm{CD} 38^{-}$cells was also investigated. In 7 of 8 samples analyzed, the number of $\mathrm{CD} 34^{+} \mathrm{CD} 38^{+}$cells positive for CD11c was low (less than 20\%) and the fluorescence was dim or, alternatively, all cells were negative. Only one sample showed around $45 \%$ of positive cells with dim fluorescence. The CD34+CD38population could be analyzed in only 5 samples due to low event numbers. The
Figure 2. Number of viable CD38- cells among viable CD34 ${ }^{+}$cells in culture. Note the logarithmic scale on the ordinate. $\mathrm{ND}=$ not determined; TPO $=$ thrombopoietin; FL $=$ FLT-3 ligand; $\mathrm{KL}=$ kit ligand.

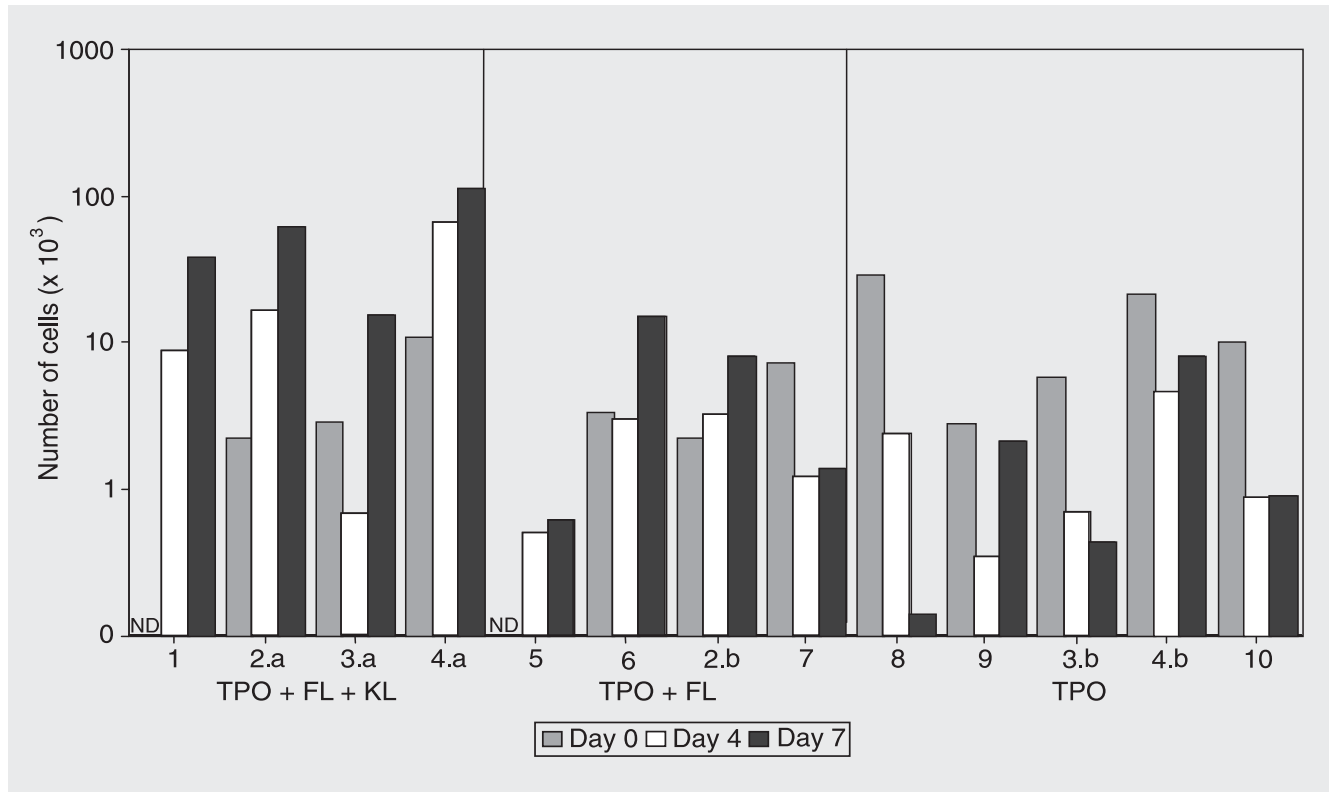


samples presented the same predominant pattern as observed for $\mathrm{CD} 34^{+} \mathrm{CD} 38^{+}$cells.

All 8 samples showed $100 \%$ of the cells positive for CD31, with a bright fluorescence, and about $70-100 \%$ of the cells with regular fluorescence for CD49e. For CD61, however, among $\mathrm{CD} 34^{+} \mathrm{CD} 38^{+}$cells either the number of positive cells was low (less than $15 \%$ ), with regular fluorescence, or $100 \%$ of the cells were negative. In one of the samples, the positive population contained a small (around 3\%) subpopulation of bright cells. Because the number of the events was low in $\mathrm{CD}^{2} 4^{+} \mathrm{CD} 38^{-}$cells, we could analyze only 4 of 8 samples.

Cells were heterogeneous for CD62L expression. About $43 \pm 17$ and $27 \pm 17 \%$ of $\mathrm{CD}^{+}{ }^{+} \mathrm{CD} 38^{+}$and $\mathrm{CD}^{+} 4^{+} \mathrm{CD} 38^{-}$cells, respectively, were positive with a regular mean fluorescence intensity. In one sample, a second population of around $20 \%$, among $\mathrm{CD} 34^{+} \mathrm{CD} 38^{+}$cells, presented bright fluorescence for CD62L. In 2 samples the number of events among CD34+CD38- cells was too low to be analyzed.

The pattern for HLA-DR was very heterogeneous among samples. This marker was present in about $54 \pm 28$ and $34 \pm 31 \%$ of $\mathrm{CD}^{+} 4^{+} \mathrm{CD} 38^{+}$and $\mathrm{CD}^{+} 4^{+} \mathrm{CD} 38^{-}$cells, respectively, with a regular mean fluorescence intensity. In one of the samples, a small population of the bright cells was also seen among the $\mathrm{CD} 34{ }^{+} \mathrm{CD} 38^{+}$population, whereas in another two populations, very few positive cells with dim and bright cells were observed.

The fluorescence pattern observed for CD117 was complex. Among CD $34^{+} \mathrm{CD} 38^{+}$ cells, two clusters could be observed, one with a high frequency of cells $(80 \pm 10 \%$, range: $59-91 \%$ ) with regular fluorescence and another composed of few cells $(6 \pm 5 \%)$ with bright or very bright fluorescence. Among the $\mathrm{CD} 34^{+} \mathrm{CD} 38^{-}$cells, $56 \pm 24 \%$ presented regular mean fluorescence intensity, with no bright cells observed.

The immunophenotypic profile of um- bilical cord blood CD $34^{+}$cells was analyzed after 4 and 7 days of culture with TPO + FL $+\mathrm{KL}, \mathrm{TPO}+\mathrm{FL}$ and TPO. In some of the samples, particularly among $\mathrm{CD} 34{ }^{+} \mathrm{CD} 38-$ cells, the analysis was not possible due to very small numbers of events. Culture with TPO + FL or TPO alone was also a factor which decreased the cell number to a level below meaningful analysis in some cases.

The patterns for CD11c, CD31, CD49e, and $\mathrm{CD} 61$ between $\mathrm{CD} 34^{+} \mathrm{CD} 38^{+}$and CD $34^{+} \mathrm{CD} 38^{-}$cells were not modified after the culture in all combinations of growth factors (data not shown). For CD62L, however, the number of positive cells and the fluorescence intensity increased from day 0 to day 4 and again from day 4 to day 7 in all culture conditions (Figure 3 ). In only one sample, cultured with TPO alone, did the number of positive cells increase from day 0 to day 4 but it decreased a little from day 4 to day 7 (data not shown).

In cultures with $\mathrm{TPO}+\mathrm{FL}+\mathrm{KL}$, the number of cells positive for HLA-DR and the intensity of fluorescence increased from the day 0 to day 4 , but decreased a little from day 4 to day 7 between $\mathrm{CD} 34^{+} \mathrm{CD} 38^{+}$and CD $34{ }^{+} \mathrm{CD} 38-$ cells (Figure 3 ). In cultures with $\mathrm{TPO}+\mathrm{FL}$, the reactivity pattern did not change among $\mathrm{CD} 34^{+} \mathrm{CD} 38^{+}$cells, except for one sample in which the number of positive cells increased from day 0 to day 4 but remained unaltered until the end of the culture. Similar patterns were observed in $\mathrm{CD} 34^{+} \mathrm{CD} 38-$ cells, but the number of events was very low. The results were heterogeneous in cells cultured with TPO alone (data not shown). Among CD $34{ }^{+} \mathrm{CD} 38^{+}$cells, the number of positive cells increased significantly in 3 samples, whereas in the remaining 2 no changes were observed. Two of the 4 samples analyzed for $\mathrm{CD} 34^{+} \mathrm{CD} 38^{-}$cells remained the same and in 2 the number of HLA-positive cells increased.

Culture with TPO + FL or TPO alone reduced the number of cells brightly positive for CD117 among $\mathrm{CD}^{2} 4^{+} \mathrm{CD} 38^{+}$cells in 
comparison with day 0 . The presence of $\mathrm{TPO}+\mathrm{FL}+\mathrm{KL}$, however, induced a decrease in CD117-positive cells (Figure 3). Among CD34 ${ }^{+} \mathrm{CD} 38-$ cells, the results were more heterogeneous. After culture with TPO $+\mathrm{FL}+\mathrm{KL}$, a cluster of few cells with dim or regular fluorescence could be observed, but no bright cells. The number of positive cells increased after culture with TPO + FL but no bright cells were seen. When TPO alone was used, two clusters were observed: a high number of cells with mean fluorescence around 100 and another one with few cells of mean fluorescence around 1000.

In some samples, after culture with TPO + FL (samples 5 and 6) or TPO alone (samples 9 and 3.b) the number of $\mathrm{CD} 34^{+} \mathrm{CD} 38^{-}$cells was too low to analyze for CD117 reactivity. On day 0, the average frequency of CD117negative cells was $44.2 \pm 26.3 \%(\mathrm{~N}=5)$. After culture with TPO + FL + KL, 84.5 \pm $11.8 \%$ of the cells were negative for CD117 on day $4(\mathrm{~N}=3)$ and $96.0 \pm 2.7 \%(\mathrm{~N}=4)$ on day 7. After culture with TPO + FL, $11.3 \pm$

Figure 3. Frequency of cells positive for CD62L/PE, CD117/ PE and HLA-DR/PE among CD $34^{+}{ }^{+}$D $38^{+}$and $\mathrm{CD} 34^{+}{ }^{+}$D $38^{-}$ cells on day 0 and after 7 days of culture with TPO + FL + KL. TPO $=$ thrombopoietin; FL $=$ FLT-3 ligand; $\mathrm{KL}=$ kit ligand. $\mathrm{PE}=$ fluorochrome phycoerythrin. $\mathrm{M} 1=$ isotype control; M2 = cells with regular fluorescence; M3 = cells with bright fluorescence.

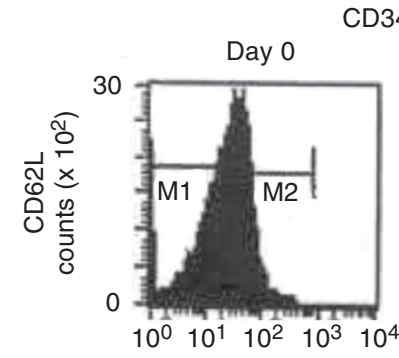

CD34+ ${ }^{+}$D $38^{+}$
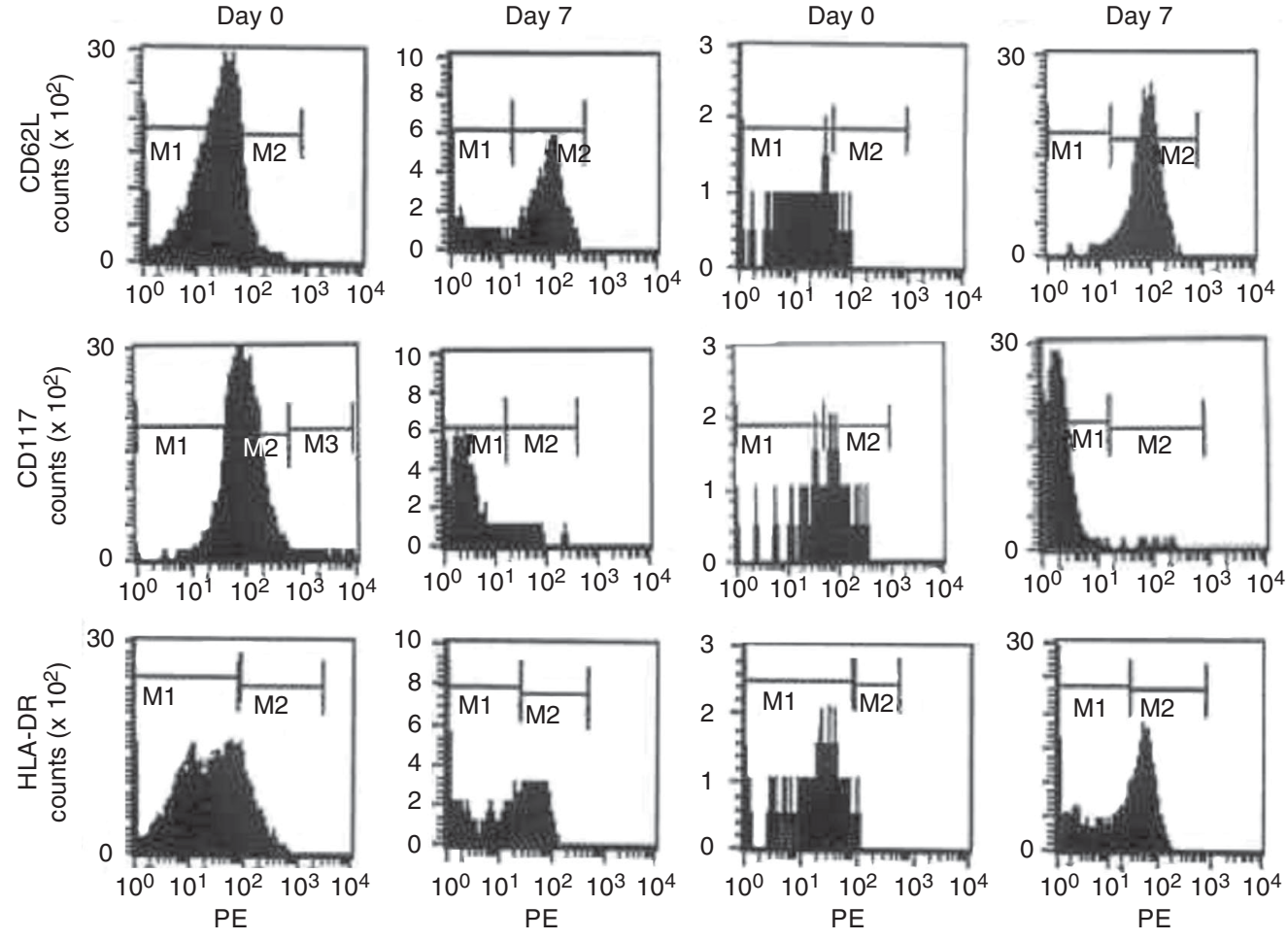

- $P E$
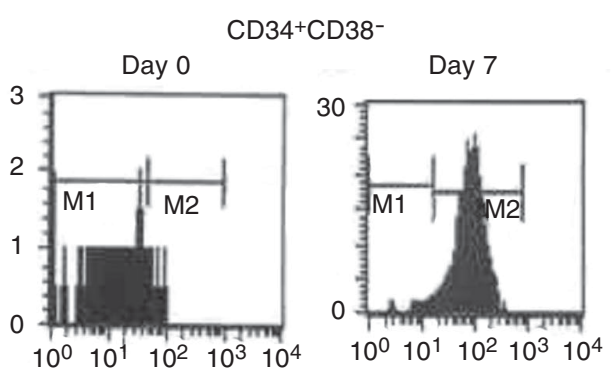

5.1 and $7.5 \pm 9.2 \%$ of the $\mathrm{CD} 34^{+} \mathrm{CD} 38^{-}$cells were CD117-negative on day $4(\mathrm{~N}=3)$ and day $7(\mathrm{~N}=2)$ respectively, whereas culture with TPO resulted in $7.3 \pm 2.1$ and $7.5 \pm$ $6.4 \% \mathrm{CD} 117$-negative cells on days $4(\mathrm{~N}=$ $3)$ and $7(\mathrm{~N}=2)$, respectively.

\section{Discussion}

Lack of CD38, HLA-DR and lineagecommitted antigens, as well as the co-expression of Thy-1 (CDw90) and c-kit receptor (CD117), have been shown to identify the candidate hemopoietic stem cells (12). However, a better knowledge and standardization of the phenotype of umbilical cord blood CD $34^{+}$cells is critical since HUCB volume is limited (13). The present study aimed to contribute to the characterization of $\mathrm{CD}_{3} 4^{+}$cells from umbilical cord blood, analyzing their phenotype and behavior before and after culture with different combinations of growth factors.

The frequency of $\mathrm{CD}^{2} 4^{+}$cells among 
HUCB MNCs in our study was $1.4 \%(0.4-$ $4.9 \%$ ), in agreement with other studies. This frequency is similar to that in harvested pelvic bone marrow $(1.0 \pm 0.3$ vs $0.8 \pm 0.4 \%)$ (14). About $1 \%$ of bone marrow cells express CD34, and generally less than $1 \%$ of these cells are CD38-negative $(6,11,15)$. In other studies, Campagnoli et al. (16) showed that the concentration of $\mathrm{CD} 34^{+}$cells in whole blood samples in term fetal blood was $0.4 \pm$ $0.03 \%$ of total CD $45^{+}$cells, and Hao et al. (3) showed that the frequency of $\mathrm{CD} 34^{+}$cells among total MNCs in cord blood was $0.36 \pm$ $0.33 \%$ with a large variation among samples (range 0.02 to $1.43 \% ; \mathrm{N}=30$ ).

In the present study, we found a large variation in the frequency of $\mathrm{CD} 34^{+}$cells among HUCB MNCs, from 0.4 to $4.9 \%$. Although correlation between total nucleated cell and CD34+ cells in HUCB has been reported, within groups of samples with similar total nucleated cell counts a high degree of variation (at times exceeding 10-fold) in CD34 ${ }^{+}$cells is observed. CD34 counts in HUCB can be as low as $0.1 \%$ of total nucleated cell as reported by Yap et al. (17), and D'Arena et al. (18) observed 0.01-1.71\% CD34 ${ }^{+}$cells among HUCB cells. Different explanations have been given for the variability found in the frequency of $\mathrm{CD} 34^{+}$cells in HUCB. There is evidence that, although the $\mathrm{CD} 34$ population frequency is a reliable indicator of the progenitor potential of HUCB, it is nevertheless heterogeneous in nature. On the other hand, these heterogeneous results can reflect differences in the sensitivity of the methods employed by the different groups. CD34 ${ }^{+}$HSCs have also been shown to vary with gestational age, mode of delivery and positioning of the delivered neonate after delivery. Yap et al. (17) found that $\mathrm{CD} 34^{+}$cells accounted for $5.1 \pm$ $1.0 \%$ of $\mathrm{CD} 45^{+}$cells in first trimester blood, significantly more than in term cord blood $(0.4 \pm 0.03 \%)$.

Controversial results have been published regarding the frequency of $\mathrm{CD} 38^{-}$cells among cord blood CD34+ cells. We found that $2.6 \pm 2.1 \%$ (range $0.55-5.57$ ) of the $\mathrm{CD}^{+} 4^{+}$cells were $\mathrm{CD} 38$-negative on day 0 , which agrees with reports showing that most CD34+ cells present the CD38 antigen in HUCB (4) and in mobilized peripheral blood cells (19). Campagnoli et al. (16) reported that the percentage of $\mathrm{CD} 34^{+}$cells which are CD38- was $3.9 \pm 0.9 \%(\mathrm{~N}=5)$, whereas $\mathrm{CD} 34^{+} \mathrm{CD} 38^{-}$cells have been reported to comprise $0.05 \pm 0.08 \%$ of the MNCs present in cord blood (3). Timeus et al. (9) observed that the number of $\mathrm{CD}^{2} 4^{+} \mathrm{CD} 38^{-}$cells was significantly higher in cord blood than in bone marrow $(16 \pm 8.8$ and $4.7 \pm 3 \%$ of total CD $34^{+}$cells, respectively). However, the number of CD38- cells among HUCB CD34+ cells was reported as $11 \%$ (18), or $34.9 \pm$ $3.4 \%$ (20).

Studies comparing the three different compartments have shown that the proportion of $\mathrm{CD} 34^{+} \mathrm{CD} 38^{-}$cells is greater in $\mathrm{HUCB}$ as compared to peripheral blood $(9,21,22)$. This might explain the successful clinical use of HUCB even when a small number of cells is used, making the presence of these antigens candidate predictive parameters for clinical use of HUCB samples (13).

The frequency of viable CD34+ cells after isolation was lower than that found, for instance, in samples processed in cord blood centers. It is possible that the extensive manipulation involved in the immunomagnetic procedure, not performed in cord blood centers, decreases cell viability. It is known that different factors involved in the processing of hematopoietic cells, such as a 48-h delay in their analysis or freezing and thawing have a negative impact on their biology (23).

Although cell numbers were higher after culture, particularly in the presence of TPO $+\mathrm{FL}+\mathrm{KL}$, and cell viability was increased or did not show a difference, the number of CD $34^{+}$cells showed a marked decrease. These results indicate that, during culture, a proportion of stem cells differentiate and lose the CD34 surface marker. In our study 
we used three different combination of hematopoietic growth factors. TPO is a primary regulator of megakaryocyte and platelet production and might also play an important role in early hematopoiesis (24). It is an important cytokine in the early proliferation of human primitive as well as committed hematopoietic progenitors, and in the ex vivo manipulation of human hematopoietic progenitors (9). TPO has also been observed to suppress apoptosis of $\mathrm{CD} 34^{+} \mathrm{CD} 38^{-}$cells in culture, showing a potential role in maintaining quiescent primitive human progenitor cells viable (25). Liu et al. (26) used a combination of growth factors with and without TPO and showed a significant expansion of $\mathrm{CD}_{34}{ }^{+}$cells from HUCB and neonatal blood to early and committed progenitors, in the presence of this factor. This potential role of TPO in the early hematopoietic differentiation was explored in the present study, in which TPO was used in all combinations of growth factors.

FL, a class III tyrosine kinase receptor expressed on primitive human and murine hematopoietic progenitor cells, is able to induce proliferation of $\mathrm{CD} 34^{+} \mathrm{CD} 38^{-}$cells that are non-responsive to other early acting cytokines and to improve the maintenance of progenitors in vitro (5). The expansion of nonadherent cells from umbilical cord blood, for instance, has been shown to be greater with $\mathrm{TPO}+\mathrm{FL}+\mathrm{KL}$ than TPO + FL, and greater in this combination than with TPO alone. Similarly, the expansion of $\mathrm{CD} 34^{+}$ CD38- was greater with $\mathrm{TPO}+\mathrm{FL}$ than with TPO alone, and the percentage of $\mathrm{CD}^{+} 4^{+}$ cells was greater with TPO + FL than with $\mathrm{TPO}+\mathrm{FL}+\mathrm{KL}$ (1). Our data agree with these results, since the absolute number of CD $34{ }^{+} \mathrm{CD} 38^{-}$cells increased considerably when TPO, FL and KL were used as growth factors. The number of those cells increased in a few samples when we used TPO and FL and decreased when we used just TPO. It has already been shown that, although TPO alone can stimulate limited clonal growth, it synergizes with the KL, FL, or IL-3 to potently enhance clonogenic growth. Ramsfjell et al. (24) showed that whereas KL and FL in combination stimulate the clonal growth of only $3 \%$ of $\mathrm{CD}^{3} 4^{+} \mathrm{CD} 38-$ cells, $40 \%$ of those cells are recruited by TPO + FL + KL, demonstrating that TPO promotes the growth of a large fraction of $\mathrm{CD} 34^{+} \mathrm{CD} 38^{-}$progenitor cells.

An interesting correlation can be made between the number of $\mathrm{CD} 34^{+} \mathrm{CD} 38^{-}$cells and total increase in cell numbers, which was directly proportional to the increase or decrease in $\mathrm{CD} 34{ }^{+} \mathrm{CD} 38-$ cells. When TPO $+\mathrm{FL}+\mathrm{KL}$ were used total cell numbers as well as $\mathrm{CD} 34^{+} \mathrm{CD} 38^{-}$cells presented a gradual increase during culture. These results indicate that self-renewal and differentiation of $\mathrm{CD} 34^{+} \mathrm{CD} 38^{-}$cells were significantly increased in the presence of TPO + FL + KL as compared to the other two combinations of growth factors.

Finally, it is interesting to observe that, although an increase in total cell counts and in $\mathrm{CD} 34^{+} \mathrm{CD} 38^{-}$cell number was induced by the growth factors, particularly in the TPO + $\mathrm{FL}+\mathrm{KL}$ combination, this increase was smaller than reported in other studies (1). In those studies, as well as in several other ones, however, cells were cultured with fetal calf serum or pooled human serum, whereas we employed serum-free media. We believe that serum-free medium allows a better control of the role that individual cytokines and their combination have on cell growth and differentiation. Furthermore, many of these studies analyze the behavior of the cells in long-term culture, whereas in the present study cells were cultured for only one week. Our aim was to expand $\mathrm{CD} 34^{+} \mathrm{CD} 38^{-}$cells within a short period of time to use the expanded population for transplants.

We investigated the expression of several cell adhesion molecules and other proteins among $\mathrm{CD} 34^{+} \mathrm{CD} 38^{+}$and $\mathrm{CD} 34^{+} \mathrm{CD} 38^{-}$ cells in umbilical cord blood, before and after culture with $\mathrm{TPO}+\mathrm{FL}+\mathrm{KL}, \mathrm{TPO}+\mathrm{FL}$ 
or TPO. Adhesion molecules play a role in the migration of hematopoietic progenitor cells and in the regulation of hematopoiesis. Cell adhesion molecules are highly expressed in both HUCB and bone marrow CD34+ CD38- cells. It has been shown that molecules such as CD11a and CD62L are more expressed in HUCB than in the bone marrow $\mathrm{CD} 34^{+} \mathrm{CD} 38^{-}$subset, suggesting a possible advantage in homing and engraftment of more undifferentiated HUCB as opposed to bone marrow HSCs (27).

The expression of CD11c on HUCB CD $34^{+}$cells in fresh samples was rare, as already reported for bone marrow (28) and HUCB (6) CD34+ cells. This adhesion molecule has a role in the linkage to receptors on stimulated endothelium (Nancy Hogg, www.ncbi.nlm.nih.gov/prow). PECAM-1 expression was observed on all CD $34^{+}$cells, with high fluorescence, in all samples. Other reports have also shown high expression of CD31 on bone marrow (28) and cord blood (6) CD $34^{+}$cells. This molecule is involved in the adhesion between cells such as endothelial cells and leukocytes (Muller WA, www.ncbi.nlm.nih.gov/prow), as well as in the interaction between hematopoietic cells and extracellular matrix components in bone marrow. CD11c and CD31 were homogeneously expressed, presenting the same pattern among $\mathrm{CD} 34^{+} \mathrm{CD} 38^{+}$or $\mathrm{CD} 34^{+} \mathrm{CD} 38$ before and after culture.

We found a large number of CD34+ $\mathrm{CD}^{2} 8^{+}$and $\mathrm{CD} 34^{+} \mathrm{CD} 38^{-}$cells positive for CD49e in all samples both before and after culture. This molecule corresponds to the $\alpha$ chain of the VLA-5 integrin, and is strongly involved in the binding of bone marrow progenitor cells to extracellular matrix components (29). It is interesting, however, that different studies report conflicting results. Asosingh et al. (28) showed that all CD34+ cells in normal bone marrow expressed CD49e, while cord blood and mobilized $\mathrm{CD}^{+} 4^{+}$cells had a lower expression of this molecule than bone marrow $\mathrm{CD} 34^{+}$cells.
On the other hand, Timeus et al. (9) showed greater expression of this molecule on CD $34^{+}$ of cord blood than bone marrow. In other studies, cord blood CD $34^{+}$cells have been reported to express VLA-5 in a pattern remarkably similar to that of bone marrow $\mathrm{CD}^{+}{ }^{+}$cells. Denning-Kendall et al. (30) showed that the expression of VLA-5 on $\mathrm{CD} 34^{+}$and $\mathrm{CD} 34^{+} \mathrm{CD} 38^{-}$cells increased after 7 days of culture with KL, FL, TPO, and G-CSF.

CD61 has been observed in small levels on HUCB CD $34^{+}$cells: less than $20 \%$ (13) or $20.2 \pm 16.1 \%$ (4). In our study, the expression of this antigen on HUCB CD34 ${ }^{+}$cells was also rare in $\mathrm{CD} 34^{+} \mathrm{CD} 38^{+}$or $\mathrm{CD} 34^{+}$ CD38- cells before and after culture. L-selectin is involved in the homing of CD34+ cells after peripheral blood MNC transplantation. The majority of the $\mathrm{CD} 34^{+}$cells had CD62L on the membrane surface. HUCB and mobilized blood $\mathrm{CD} 34^{+}$have been shown to present a higher expression of CD62L than bone marrow $\mathrm{CD} 34^{+}$cells (28). CD62L was also more frequently expressed in the $\mathrm{HUCB}$ than in the bone marrow $\mathrm{CD} 34^{+} \mathrm{CD} 38^{-}$ subset, suggesting a possible advantage in homing and engraftment $(9,27)$. In the present study, CD62L expression was heterogeneous, and the $\mathrm{CD} 34^{+} \mathrm{CD} 38^{+}$population presented a slightly higher frequency of positive cells. Surbek et al. (31) showed that $\mathrm{CD} 62 \mathrm{~L}$ on $\mathrm{CD} 34^{+}$stem and progenitor cells in umbilical cord blood change during gestation. This could explain the great variability in the frequency of CD62L-positive cells observed in different samples, since in the present study the gestational age presented a range from 29 weeks to term.

An interesting effect was observed for the expression of CD62L after culture. The number of CD62L-positive CD34+CD38cells and the CD62L expression on these cells increased during culture in all conditions. Denning-Kendall et al. (30) have also found increased expression of L-selectin (or CD62L) on $\mathrm{CD}^{+} 4^{+}$and $\mathrm{CD} 34^{+} \mathrm{CD} 38^{-}$cells 
after 7 days of culture with KL, FL, TPO, and G-CSF.

Timeus et al. (9) have shown that a short exposure to cytokines increases L-selectin expression in the more differentiated hematopoietic progenitors, $\mathrm{CD} 34^{+} \mathrm{CD} 38^{+}$cells, which could improve their homing in a transplant setting. After transplantation of HSCs, adhesion molecules play a major role in the multistep process of engraftment in which $\mathrm{L}$-selectin is suggested to be of relevance. Gigant et al. (32) showed a higher frequency of CD62L-positive cells in peripheral blood than in bone marrow or cord blood, and Young et al. (33) reported increased expression of CD62L expression on mobilized peripheral blood $\mathrm{CD}_{3} 4^{+}$cells cultured with $\mathrm{TPO}+\mathrm{FL}+\mathrm{KL}$. The present study showed a significant increase of $\mathrm{L}$-selectin-positive cells, suggesting improved homing ability in HUCB cultured with growth factors in all combinations.

There is evidence that cord blood, bone marrow and peripheral blood-derived HSCs are highly heterogeneous for a number of antigens useful for HSC enumeration by flow cytometry (6). HLA-DR is expressed in the majority of $\operatorname{HUCB}(4,13)$ and peripheral blood $(13,19) \mathrm{CD}^{3} 4^{+}$cells. While De Bruyn et al. (21) showed that the co-expression of CD34 with HLA-DR was not significantly different in HUCB and bone marrow (86.3 \pm 2.7 and $92.7 \pm 5.1 \%$, respectively), Cho et al. (22) showed that CD34+HLA-DR ${ }^{+}$cell frequencies did not differ significantly between those two compartments and MNCs. Very heterogeneous results were found for HLADR in the present study which, due to the small number of cells in some of the experimental conditions, made their interpretation difficult. The great heterogeneity of positive cells in fresh samples, as well as small differences after culture, could be explained by different gestational ages. Fetal liver cells, for instance, have been shown to present lower proportions of CD34 ${ }^{+} \mathrm{HLA}-\mathrm{DR}^{+}$than HUCB, showing that the composition of fetal leukocytes changes during development and with gestational age (34). The frequency of HLA-DR-positive cells was a little higher among $\mathrm{CD} 34{ }^{+} \mathrm{CD} 38^{+}$than $\mathrm{CD} 34^{+} \mathrm{CD} 38^{-}$cells. This result supports the conclusion that these molecules are more expressed in more differentiated cells.

The expression of c-kit (CD117) on $\mathrm{CD} 34^{+} \mathrm{CD} 38^{+}$cells separated the cells into two populations in all samples, with more than $60 \%$ of the cells showing regular fluorescence, and a small population of bright or very bright cells. In this way, three fractions were described: negative cells, cells with regular fluorescence, and cells with high fluorescence. Among CD34+CD38- cells, however, the frequency of c-kit-positive cells was slightly lower and bright cells were not observed. Although the number of samples in the present study was relatively small, the results show that, after culture with TPO + $\mathrm{FL}+\mathrm{KL}$, the number of CD34+CD38-CD117cells increased. This number decreased when we used TPO + FL or TPO alone. Culture of $\mathrm{CD} 34^{+}$cells with $\mathrm{TPO}+\mathrm{FL}+\mathrm{KL}$ thus significantly increases the number of candidate stem cells with the $\mathrm{CD} 34^{+} \mathrm{CD} 38^{-}$(c-kit) phenotype. On the other hand, the down-regulation of c-kit may be due to the presence of $\mathrm{KL}$ in the growth factor combination, since this factor was essential to expand CD34+ CD38- cells.

The most primitive human hematopoietic progenitor cells have demonstrated coexpression of c-kit, FLT-3 and Thy-1, being negative for HLA-DR, CD38 and lineage markers $(12,24)$. CD117 expression has thus been reported to characterize true stem cells (35). The c-kit receptor, a member of the Ig superfamily of adhesion molecules, is involved in the interactions of $\mathrm{CD} 34^{+}$cells with other cells and stroma in bone marrow, mobilized peripheral blood and HUCB. The c-kit receptor was detected on the majority of $\mathrm{CD} 34^{+} \mathrm{HSCs}$, particularly on HUCB in the studies of D'Arena et al. (12). On the other hand, Sakabe et al. (19) showed that 
the expression of the c-kit receptor on mobilized peripheral blood $\mathrm{CD} 34^{+}$cells was approximately $20 \%$ of that on bone marrow- or HUCB-derived CD34+ ${ }^{+}$cells which express high levels of c-kit receptor.

Studies about the expression of c-kit on mobilized peripheral blood $\mathrm{CD} 4^{+}$cells showed three fractions, namely $\mathrm{CD} 34^{+} \mathrm{c}-$ $\mathrm{kit}^{\text {high }}, \mathrm{CD} 34^{+} \mathrm{c}-\mathrm{kit}^{\text {low }}$ and $\mathrm{CD} 34^{+} \mathrm{c}-\mathrm{kit}^{-}$cells (19). Different levels of CD117 antigen were also shown in HUCB. While Gunji et al. (36) demonstrated that myeloid progenitors are enriched in $\mathrm{CD} 34^{+} \mathrm{c}$-kit ${ }^{\text {high }}$ cells and erythroid progenitors are more enriched in $\mathrm{CD} 34^{+}$ c-kit ${ }^{\text {low }}$ cells, Sakabe et al. (19) showed that erythroid progenitors are highly enriched in mobilized peripheral blood $\mathrm{CD} 34^{+} \mathrm{c}-\mathrm{kit}^{\mathrm{high}}$ cells, and that CFU-GM is enriched in mobilized peripheral blood $\mathrm{CD}^{2} 4^{+} \mathrm{c}$-kit ${ }^{-}$cells. Primitive progenitors with self-renewal potential may be present in the mobilized peripheral blood $\mathrm{CD} 34^{+} \mathrm{c}-\mathrm{kit}^{-}$or $\mathrm{CD} 34^{+} \mathrm{c}$-kit ${ }^{\text {low }}$ cell population. Laver et al. (37) reported that the HUCB-derived $\mathrm{CD} 34^{+} \mathrm{c}$-kit ${ }^{\text {low }}$ cell population contains the majority of quiescent progenitors and blast cell colony forming cells. Thus, the $\mathrm{CD} 34^{+} \mathrm{CD} 38^{-}$or $\mathrm{CD} 34^{+} \mathrm{c}-$ kit or low immunophenotype defines primitive progenitor cells in fetal liver, fetal bone marrow, adult bone marrow, mobilized peripheral blood, and HUCB (19). The expression of c-kit may therefore be useful in identifying HUCB progenitors with long-term engraftment capability (37).

HUCB has recently been explored as an alternative HSC source for allogeneic transplantation in both adults and pediatric patients with hematological malignancies and marrow failure syndromes. HUCB transplantation is particularly important in patients who lack HLA-matched marrow donors, permitting the use of HLA-mismatched grafts at 1-2 loci (or antigens) without higher risk for severe graft-versus-host disease relative to bone marrow transplantation from a fullmatched unrelated donor (38). Since the first case reported in 1988, more than 3700 pa- tients have received HUCB transplants for a variety of malignant and non-malignant diseases. Due to the relatively low number of stem cells in HUCB, limited by the blood volume which can be collected, the vast majority of recipients $(2 / 3)$ were children with an average weight of $20 \mathrm{~kg}$ (www.netcord.org). The ex vivo expansion of HSCs thus represents an attractive approach to overcoming the current limitations regarding adult HUCB transplantation.

CD34 selection and ex vivo expansion of HUCB prior to transplantation are feasible. Serum-free media, in some cases with complementation of growth factors such as TPO, KL and FL $(39,40)$, have been shown to allow the expansion and transplantation of HSCs. The ex vivo expansion of HUCB hematopoietic stem and progenitor cells has been shown, for instance, to increase cell dose and reduce the severity and duration of neutropenia and thrombocytopenia after transplantation. Additional accrual, however, will be required to assess the clinical efficacy of expanded HUCB progenitors. Some studies have shown that the ex vivo expansion of cord blood CD $34^{+}$cells results in the generation of increased mature cells and progenitors that are capable of more rapid engraftment in fetal sheep compared to unexpanded HUCB CD34+ cells (39). Enumeration of $\mathrm{CD} 34^{+} \mathrm{CD} 38$ - cells is correlated with the number of committed progenitors and the capacity of generating CD $34^{+}$cells. This is an important parameter if expansion protocols are to be used in clinical transplantation, since $\mathrm{CD} 34^{+} \mathrm{CD} 38^{-}$cells are a good predictive marker of cloning ability and expansion potential of $\mathrm{CD} 34^{+}$cord blood cells (40).

In conclusion, in this study the results indicating that culture of HUCB CD $34^{+}$cells with the combination $\mathrm{TPO}+\mathrm{FL}+\mathrm{KL}$ induced an increase in total cell counts as well as in $\mathrm{CD} 34^{+} \mathrm{CD} 38$ - cell number suggest that this growth factor combination induces an expansion of very primitive stem cells. The 
use of allogeneic cord blood products as a source of cellular support for patients receiving high-dose chemotherapy has been limited primarily by the low numbers of cells in a HUCB unit. The results of the present study and others, however, show that the true stem cell can be expanded in vitro. Furthermore, our data show that the discrepancy between current in vitro and in vivo read-out systems to assess candidate stem cells may be affected by changes in adhesion molecules. Further studies should determine what culture conditions and cell populations are needed for a range of clinical applications, improving the use of cord blood for transplantation in adults.

\section{References}

1. Piacibello W, Sanavio F, Garetto L et al. (1997). Extensive amplification and self-renewal of human primitive hematopoietic stem cells from cord blood. Blood, 89: 2644-2653.

2. Lakshmipathy U \& Verfaillie C (2005). Stem cell plasticity. Blood Reviews, 19: 29-38.

3. Hao QL, Shah AJ, Thiemann FT et al. (1995). A functional comparison of CD34+CD38- cells in cord blood and bone marrow. Blood, 86: 3745-3753.

4. Malangone W, Belvedere O, Astori G et al. (2001). Increased content of CD34+CD38- hematopoietic stem cells in the last collected umbilical cord blood. Transplantation Proceedings, 33: 1766-1768.

5. Shah AJ, Smogorzewska EM, Hannum C et al. (1996). Flt3 ligand induces proliferation of quiescent human bone marrow $\mathrm{CD} 34^{+} \mathrm{CD} 38^{-}$ cells and maintains progenitor cells in vitro. Blood, 87: 3563-3570.

6. Pranke P, Failace RR, Allebrandt WF et al. (2001). Hematologic and immunophenotypic characterization of human umbilical cord blood. Acta Haematologica, 105: 71-76.

7. McNiece IM \& Briddell R (2001). Ex vivo expansion of hematopoietic progenitor cells and mature cells. Experimental Hematology, 29: 311.

8. Yoshida M, Tsuji K, Ebihara Y et al. (1997). Thrombopoietin alone stimulates the early proliferation and survival of human erythroid, myeloid and multipotential progenitors in serum-free culture. British Journal of Haematology, 98: 254-264.

9. Timeus F, Crescenzio N, Basso G et al. (1998). Cell adhesion molecule expression in cord blood CD34+ cells. Stem Cells, 16: 120-126.

10. Nardi NB \& Costa ZZA (1999). The hematopoietic stroma. Brazilian Journal of Medical and Biological Research, 32: 601-609.

11. Pranke P, Hendrikx J, Debnath G et al. (2001). Culture of CD34+ cells from placental/umbilical cord blood. Blood, 98 (Suppl 1) 658a: 2758 (Abstract).

12. D'Arena G, Musto P, Cascavilla N et al. (1998). Thy-1 (CDw90) and c-kit receptor (CD117) expression on CD34+ hematopoietic progenitor cells: a five dimensional flow cytometric study. Haematologica, 83: 587-592.

13. Belvedere O, Feruglio C, Malangone W et al. (1999). Phenotypic characterization of immunomagnetically purified umbilical cord blood CD34+ cells. Blood Cells, Molecules, and Diseases, 25: 141-146.

14. Kinniburgh D \& Russel NH (1993). Comparative study of CD34positive cells and subpopulations in human umbilical cord blood and bone marrow. Bone Marrow Transplantation, 12: 489-494.

15. Kipps TJ (2001). The cluster of differentiation antigens. In: Williams JW (Editor), Hematology. 6th edn. McGraw-Hill, New York.

16. Campagnoli C, Fisk N, Overton T et al. (2000). Circulating hematopoietic progenitor cells in first trimester fetal blood. Blood, 95:
1967-1972.

17. Yap C, Loh MT, Heng KK et al. (2000). Variability in CD34+ cell counts in umbilical cord blood: implications for cord blood transplants. Gynecologic and Obstetric Investigation, 50: 258-259.

18. D'Arena G, Musto P, Cascavilla N et al. (1996). Human umbilical cord blood: immunophenotypic heterogeneity of CD34+ hematopoietic progenitor cells. Haematologica, 81: 404-409.

19. Sakabe H, Ohmizono Y, Tanimukai S et al. (1997). Functional differences between subpopulations of mobilized peripheral bloodderived CD34+ cells expressing different levels of HLA-DR, CD33, CD38 and c-kit antigens. Stem Cells, 15: 73-81.

20. Almici C, Carlo-Stella C, Wagner JE et al. (1997). Biologic and phenotypic analysis of early hematopoietic progenitor cells in umbilical cord blood. Leukemia, 11: 2143-2149.

21. De Bruyn C, Delforge A, Bron D et al. (1995). Comparison of the coexpression of CD38, CD33 and HLA-DR antigens on CD34+ purified cells from human cord blood and bone marrow. Stem Cells, 13: 281-288.

22. Cho SH, Chung IJ, Lee JJ et al. (1999). Comparison of CD34+ subsets and clonogenicity in human bone marrow, granulocyte colony-stimulating factor-mobilized peripheral blood, and cord blood. Journal of Korean Medical Science, 14: 520-525.

23. Van Haute I, Lootens N, De Smet S et al. (2004). Viable CD34+ stem cell content of a cord blood graft: which measurement performed before transplantation is most representative? Transfusion, 44: 547554.

24. Ramsfjell V, Borge OJ, Cui L et al. (1997). Thrombopoietin directly and potently stimulates multilineage growth and progenitor cell expansion from primitive $\left(\mathrm{CD} 34^{+} \mathrm{CD} 38^{-}\right)$human bone marrow progenitor cells. Journal of Immunology, 158: 5169-5177.

25. Borge OJ, Ramsfjell V, Cui L et al. (1997). Ability of early acting cytokines to directly promote survival and suppress apoptosis of human primitive CD34+CD38- bone marrow cells with multilineage potential at the single-cell level: key role of thrombopoietin. Blood, 90: 2282-2292.

26. Liu J, Li K, Yuen PM et al. (1999). Ex vivo expansion of enriched CD34+ cells from neonatal blood in the presence of thrombopoietin, a comparison with cord blood and bone marrow. Bone Marrow Transplantation, 24: 247-252.

27. Timeus F, Crescenzio N, Marranca D et al. (1998). Cell adhesion molecules in cord blood hematopoietic progenitors. Bone Marrow Transplantation, 22 (Suppl 1): S61-S62.

28. Asosingh K, Renmans W, Van der Gucht K et al. (1998). Circulating CD34+ cells in cord blood and mobilized blood have a different profile of adhesion molecules than bone marrow CD34+ cells. European Journal of Haematology, 60: 153-160. 
29. Coulombel L, Auffray I, Gaugler MH et al. (1997). Expression and function of integrins on hematopoietic progenitor cells. Acta Haematologica, 97: 13-21.

30. Denning-Kendall P, Singha S, Bradley B et al. (2003). Cytokine expansion culture of cord blood $\mathrm{CD}_{3} 4^{+}$cells induces marked and sustained changes in adhesion receptor and CXCR4 expressions. Stem Cells, 21: 61-70.

31. Surbek DV, Steinmann C, Burk M et al. (2000). Developmental changes in adhesion molecule expressions in umbilical cord blood CD34 hematopoietic progenitor and stem cells. American Journal of Obstetrics and Gynecology, 183: 1152-1157.

32. Gigant C, Latger-Cannard V, Bensoussan D et al. (2003). CD34+ cells homing: quantitative expression of adhesion molecules and adhesion of CD34+ cells to endothelial cells exposed to shear stress. Biorheology, 40: 189-195.

33. Young JC, Lin K, Travis M et al. (2001). Investigation into an engraftment defect induced by culturing primitive hematopoietic cells with cytokines. Cytotherapy, 3: 307-320.

34. Kilpatrick DC, Atkinson AP, Palmer JB et al. (1998). Developmental variation in stem-cell markers from human fetal liver and umbilical cord blood leukocytes. Transfusion Medicine, 8: 103-109.
35. Papayannopoulou T, Brice M, Broudy VC et al. (1991). Isolation of Ckit receptor-expressing cells from bone marrow, peripheral blood, and fetal liver: functional properties and composite antigenic profile. Blood, 78: 1403-1412.

36. Gunji Y, Nakamura M, Osawa H et al. (1993). Human primitive hematopoietic progenitor cells are more enriched in KITlow cells than KIThigh cells. Blood, 82: 3283-3289.

37. Laver JH, Abboud MR, Kawashima I et al. (1995). Characterization of c-kit expression by primitive hematopoietic progenitors in umbilical cord blood. Experimental Hematology, 23: 1515-1590.

38. Laughlin MJ, Eapen M, Rubinstein P et al. (2005). Outcomes after transplantation of cord blood or bone marrow from unrelated donors in adults with leukemia. Obstetrical and Gynecological Survey, 60: 295-296.

39. McNiece IK, Almeida-Porada G, Shpall EJ et al. (2002). Ex vivo expanded cord blood cells provide rapid engraftment in fetal sheep but lack long-term engrafting potential. Experimental Hematology, 30: 612-616.

40. Encabo A, Mateu E, Carbonell-Uberos F et al. (2003). CD34+CD38is a good predictive marker of cloning ability and expansion potential of CD34+ cord blood cells. Transfusion, 43: 383-389. 